\title{
(2) OPEN ACCESS \\ Imaging with ultrasound in physical therapy: What is the PT's scope of practice? A competency-based educational model and training recommendations
}

\author{
Jackie L Whittaker 자, ${ }^{1}$ Richard Ellis, ${ }^{2}$ Paul William Hodges $\left(10,{ }^{3}\right.$ Cliona OSullivan, \\ Julie Hides, ${ }^{5}$ Samuel Fernandez-Carnero, ${ }^{6}$ Jose Luis Arias-Buria, ${ }^{7}$ Deydre S Teyhen, ${ }^{8}$ \\ Maria J Stokes ${ }^{9}$
}

\begin{abstract}
- Additional material is published online only. To view please visit the journal online (http://dx.doi.org/10.1136/ bjsports-2018-100193)

For numbered affiliations see end of article.
\end{abstract}

\section{Correspondence to}

Dr Jackie L Whittaker, Faculty of Rehabilitation Medicine, University of Alberta, Edmonton, AB T6G 2G4, Canada; jwhittak@ualberta.ca

Accepted 25 March 2019 Published Online First 25 April 2019
Check for updates

(C) Author(s) (or their employer(s)) 2019. Re-use permitted under CC BY. Published by BMJ.

\section{To cite: Whittaker JL,}

Ellis R, Hodges PW

et al. Br J Sports Med

2019:53:1447-1453.

\section{ABSTRACT}

Physical therapists employ ultrasound (US) imaging technology for a broad range of clinical and research purposes. Despite this, few physical therapy regulatory bodies guide the use of US imaging, and there are limited continuing education opportunities for physical therapists to become proficient in using US within their professional scope of practice. Here, we (i) outline the current status of US use by physical therapists; (ii) define and describe four broad categories of physical therapy US applications (ie, rehabilitation, diagnostic, intervention and research US); (iii) discuss how US use relates to the scope of high value physical therapy practice and (iv) propose a broad framework for a competency-based education model for training physical therapists in US. This paper only discusses US imagingnot 'therapeutic' US. Thus, 'imaging' is implicit anywhere the term 'ultrasound' is used.

\section{BACKGROUND}

Many physical therapists embrace ultrasound (US) imaging as a means to deliver precise and personalised rehabilitation. Since the first published use of US by physical therapists (1980), ${ }^{1-5}$ there have been three notable milestones in the evolution of US use by physical therapists; a series of commentaries $^{6-8}$ and original research published after the first International Symposium on Rehabilitative Ultrasound Imaging (RUSI; hosted by the US ArmyBaylor University Doctoral Programme in Physical Therapy, Fort Sam Houston, Texas, 2006), ${ }^{9}$ a networking session at the International Federation of Orthopaedic Manipulative Physical Therapists conference (Quebec City, Canada, 2012) ${ }^{10}$ and a second (although not affiliated) international symposium hosted by the Universidad Francisco de Vitoria and the Spanish Society of Ultrasound in Physiotherapy (Madrid, Spain, 2016). ${ }^{11}$ Despite these efforts, there remains considerable confusion and inconsistencies in terminology associated with physical therapist use of US due, in part, to the diversity of manners in which US is used across the profession. It is also clear that previously identified gaps related to scope of practice (a statement describing physical therapy within the context of the regulatory environment and the evidence base for practice within a jurisdiction. Scopes of practices are dynamic and evolving in accordance with changes in the evidence base, policy and needs of service users) ${ }^{12}$ and specialised training are growing.

At the time of the 2006 symposium, the majority of reported uses of US by physical therapists involved the evaluation of muscle structure (morphology) and function, or as a source of biofeedback to aid rehabilitation of neuromuscular control. The term RUSI was coined to encompass these applications, and along with a definition (see below) an accompanying visual representation (figure 1) of how the practice of RUSI fits into the larger field of medical US was developed.

Since 2006, three additional distinct categories of physical therapist use of US beyond RUSI have been identified. These applications include the following: diagnosing and monitoring pathology (diagnostic US); guiding percutaneous procedures involving 'dry' (eg, acupuncture) or 'wet' (eg, injection) needles (interventional US); and undertaking research (research US; see figure 2).

The three clinical categories (ie, rehabilitative, diagnostic and interventional US) of US use fall under the umbrella of 'Point-of-Care Ultrasound' defined as an ultrasound examination performed by a qualified healthcare practitioner, usually as an adjunct to a physical examination, to clarify uncertain findings, or provide image guidance that improves the success and safety of procedures in the acute care setting, particularly when time saving for diagnosis or treatment is critical. ${ }^{13}$ Point-of-care contrasts US evaluations performed in a dedicated imaging facility, or department, in a consultative process between the treating healthcare practitioner and a consulting imaging specialist. In the physical therapy context, point-of-care US can be defined as a form of examination using US undertaken in a clinical practice setting with the intent of clarifying uncertain clinical examination findings to enhance the quality and effectiveness of a physical therapy intervention. Given that physical therapy point-ofcare US examinations fall within the scope of physical therapy practice and competence (knowledge, skills and abilities) of the examining therapist (as per the regulations of their jurisdiction), it is essential that it is understood that they are performed to direct a physical therapy intervention, not to provide a medical diagnosis or direct medical treatment.

Below, we define and describe the four broad categories of physical therapy US applications, discuss implications of the use of US by physical 


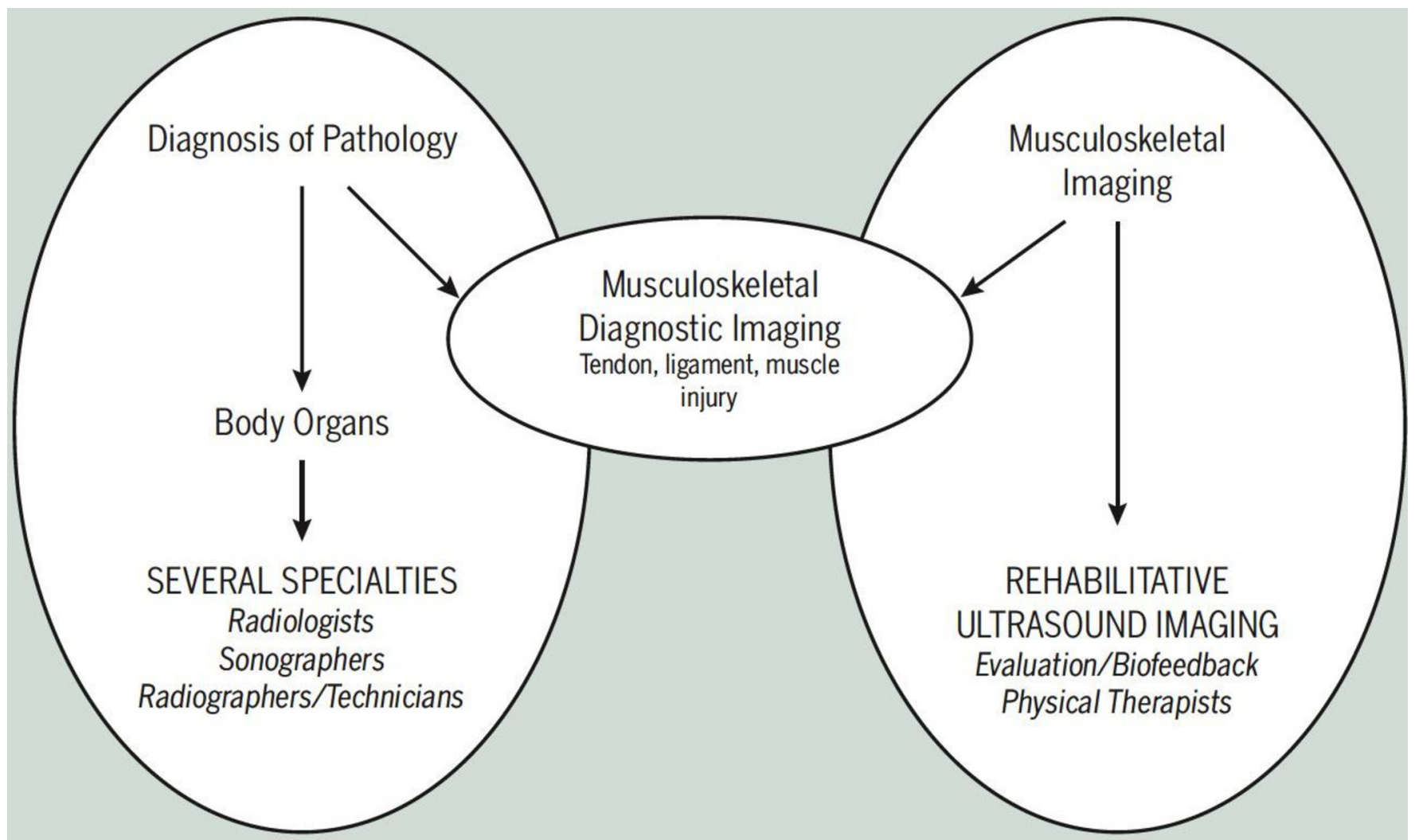

Figure 1 A visual representation of how the practice of RUSI evolved to fit into the larger field of medical us in $2006 .{ }^{12}$ Reproduced with permission from the J Orthop sports Phys ther.

therapists on scope of practice and training, and propose a broad framework for a competency-based education model for training physical therapists in US use.

\section{USES OF US BY PHYSICAL THERAPISTS}

This section proposes definitions and provides descriptions and examples of each of the four broad categories of physical therapy US applications outlined in figure 2.

\section{Rehabilitative US imaging}

The most common uses of US by physical therapists reported in the literature fall within the realm of RUSI and have involved studies of the musculoskeletal system in a variety of settings (eg, sports medicine, orthopaedics, occupational, respiratory and pelvic health). Rehabilitative US was originally defined as a procedure used by physical therapists to evaluate muscle and related soft tissue morphology and function during exercise and physical tasks... and to assist in the application of therapeutic interventions aimed at improving neuromuscular function. ${ }^{9}$ This includes measuring muscle morphology (eg, length, thickness, diameter, cross-sectional area, volume, fascicle length and penation angle $)^{14}$; changes or differences in muscle morphology over time (eg, with ageing), ${ }^{15}$ between groups of people ${ }^{16}$ or with events (eg, contraction, ${ }^{17}$ injury, ${ }^{18}$ surgery, ${ }^{19}$ exposure to microgravity ${ }^{20}$; assessing the impact of muscle contraction on adjacent structures (movement and deformation of fascia, ${ }^{21}$ nerve, ${ }^{22}$ linea alba ${ }^{23}$ and visceral organs such as the bladder ${ }^{8}$ and urethra ${ }^{24}$; evaluating muscle composition ${ }^{25}$; and providing biofeedback. ${ }^{26}$ In the context of musculoskeletal and sports physical therapy, RUSI has been used to assess trunk muscle size and contraction to screen for injury risk, ${ }^{27} 28$ provide feedback and measure changes in muscle size as a result of injury prevention programmes ${ }^{29}$ or in response to conditioning ${ }^{30}$ or therapeutic interventions. ${ }^{31}$ In the context of pelvic health, RUSI has been used to understand, ${ }^{8}$ predict ${ }^{32} 33$ and manage urinary incontinence. ${ }^{34}$

\section{Diagnostic US imaging}

Diagnostic US involves examining the effects of injury, lesion or disease on joint surfaces, muscle, tendon, ligament, bursa, vessels, nerves and solid visceral organs. ${ }^{35}$ Traditionally, these applications have fallen under the scope of a consulting imaging specialist (ie, radiologist or sonographer). Given that US is the most cost-effective, safe and rapid method of obtaining static and real-time images, many healthcare professions have embraced the technology for point-of-care applications. In the context of physical therapy, diagnostic US has been used to identify tendon abnormalities, to screen for tendinopathy risk, ${ }^{36}$ and assess humeral torsion or acromiohumeral distance in persons with rotator cuff pathology, ${ }^{14}$ haemarthrosis within the joints of persons with haemophilia, ${ }^{37} 38$ nerve excursion in entrapment neuropathy ${ }^{39}$ or ligament integrity after injury ${ }^{40}$ to inform rehabilitation. Although many physical therapists are appropriately trained in point-of-care diagnostic US, this application may be the most controversial given the potential overlap with other healthcare practitioners. A recent New Zealand survey highlighted that many physical therapists report confusion regarding their scope for diagnostic US applications. $^{41}$

\section{Interventional US imaging}

Interventional US involves using gray-scale brightness-mode (b-mode) US to accurately, efficiently and safely guide 'dry' and 'wet' needles for a variety of invasive interventions including 


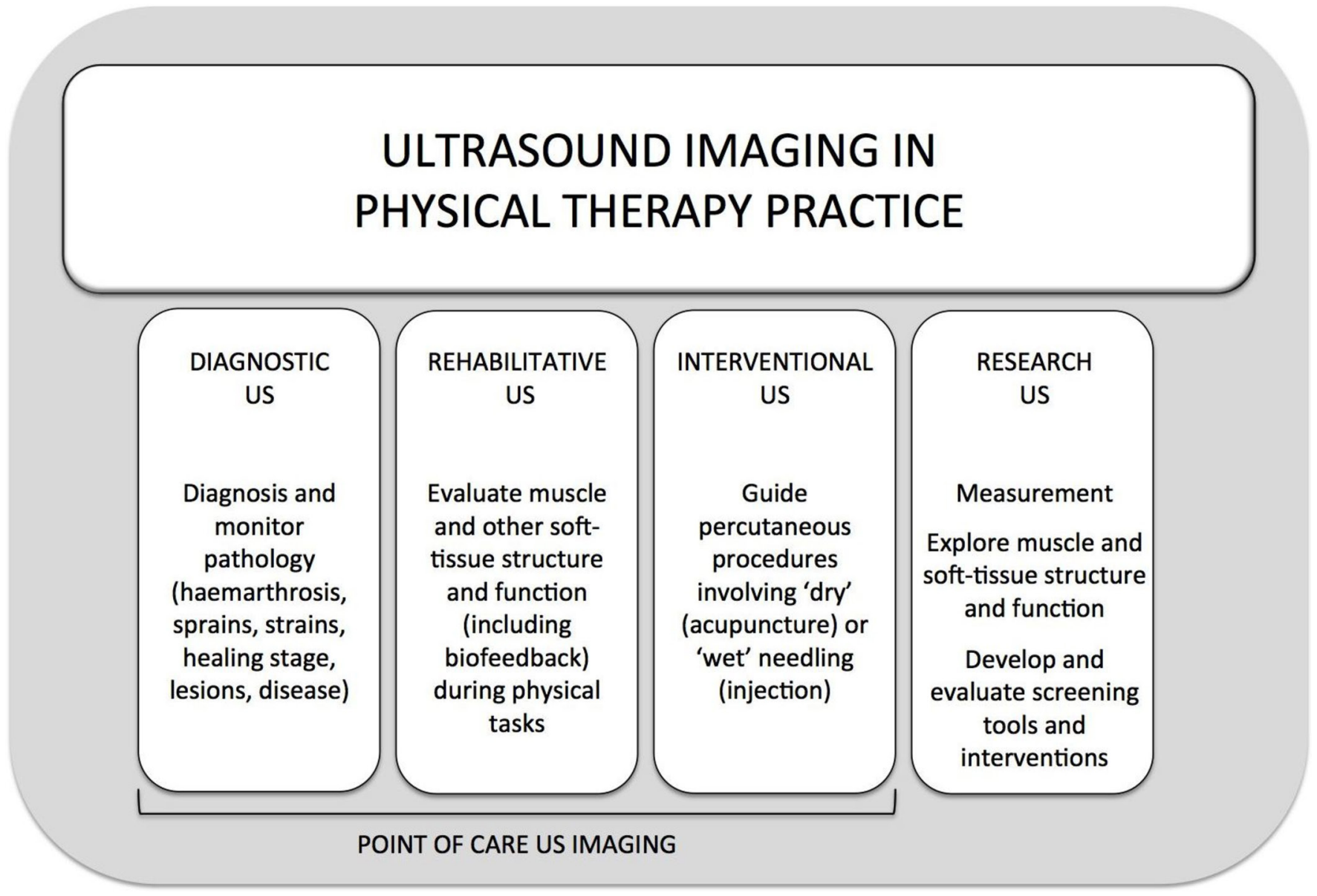

Figure 2 Current categories of US imaging use by physical therapists. US, ultrasound

acupuncture, dry needling, percutaneous electrolysis, injection or aspiration. US-guided needling and injections have been shown to be more accurate and efficacious than landmarkguided injections. ${ }^{42}$ Although physical therapy practice acts vary globally, in regions where therapists are allowed to use dry and wet needles, interventional US has been employed to safely guide dry needles for acupuncture, ${ }^{43}$ trigger point 'release', ${ }^{4}$ and percutaneous electrolysis (ie, application of mechanical stimulation and electric current through an acupuncture needle theorised to provide controlled microtrauma to stimulate tissue repair). ${ }^{45} 46$

\section{Research US imaging}

US is used in basic, applied and clinical research that aims to inform physical therapy practice. For example, US has been used to improve our understanding of the impact of pain and injury on motor control ${ }^{47}$ and muscle morphology, ${ }^{18}$ and the relationship between motor control and function, ${ }^{48}$ to determine which patients may benefit from a specific treatment approach, ${ }^{31}$ and to enhance motor learning and treatment efficacy via augmented feedback. ${ }^{49}$ More sophisticated applications of US have been used to elucidate the mechanisms underlying dry needling techniques, ${ }^{50}$ measure the excursion of nerves with movement, ${ }^{51}$ assess the biomechanical parameters (ie, stiffness) of soft tissues ${ }^{5253}$ and how this is changed by treatment, ${ }^{54}$ the dynamics of pelvic floor muscle contraction, ${ }^{24}$ and effectiveness of physical therapy interventions. ${ }^{55}$ Similar to image-guided interventions, US has been used for many years to guide insertion of intramuscular electromyography electrodes into muscles that are deep, ${ }^{48}$ small $^{56}$ or associated with high risk (eg, diaphragm. ${ }^{57}$ Beyond these applications, there is a large body of literature assessing the reliability and validity of US for examining various muscles, ${ }^{58-61}$ and nerves, ${ }^{22}$ as well as the application of US into physical therapy practice. $^{62}$

\section{US technologies and display modes}

It is important to note that within each of the four categories of physical therapy US applications, a variety of US-based imaging techniques can be used depending on the clinical or research goal. For example, gray-scale b-mode and motion (m)-mode US may be used to measure the morphological characteristics of a muscle, ${ }^{63}$ identify boney changes associated with lateral epicondylalgia ${ }^{64}$ or guide an acupuncture needle. ${ }^{45}$ In contrast, real-time Doppler US allows for dynamic high-resolution evaluations of tendon neovascularity. ${ }^{65}$ Elastography enables the quantification of the biomechanical properties (ie, stiffness) of soft tissues (eg, muscle, tendon, ligament) and subsequently may have a role in assessing the effectiveness of physical therapy interventions ${ }^{3154}$ or stages of tissue healing. ${ }^{66}$

\section{IMPLICATIONS FOR SCOPE OF PRACTICE, REGULATION AND TRAINING}

In addition to a lack of regulatory oversight, surveys conducted in the UK, ${ }^{67}$ Australia $^{68}$ and New Zealand ${ }^{41}$ demonstrate that there is no internationally accepted curricula for physical therapists training in US, with continuing education or 
mentoring opportunities varying widely across countries, and no minimal competency required for using US for patient care. One explanation for these gaps is that unlike diagnostic and interventional US, RUSI is a relatively new application and one that sits almost entirely within the scope of the physical therapy profession (sports scientists, sport therapists and osteopaths also perform RUSI applications). Faced with the rapid growth of US use by physical therapists over the last decade, the profession is faced with a situation in which its traditional scope is being challenged to evolve. Clear and consistent guidance from regulatory and professional associations could assist in mitigating these gaps and confusion.

Each category of physical therapy US is associated with unique knowledge, skill sets and potential for perceived infringement with the scope of other healthcare practitioners. Although there is some foundational overlapping concepts, the issues and barriers associated with specialised training, competent use and reporting of these applications differ. In the fields of diagnostic and interventional US, there are established criteria for training, competent use and regulation, as outlined by the $\mathrm{WHO},{ }^{69}$ and international oversight from the World Federation for Ultrasound in Medicine and Biology. Physical therapists wanting to become skilled in the use of diagnostic and interventional US can access training through existing channels consistent with these standards. With that said, it is acknowledged that in some countries there may be limited access to these established training pathways afforded to physical therapists, and existing educational models may not include physical therapy-specific applications. It is also important to consider that the practice of physical therapists gaining their US training through courses established for other healthcare practitioners (eg, radiologists, sport and exercise medicine physicians, sonographers) may lead to physical therapists operating outside of their professional scope of practice due to an increased familiarity with non-physical therapy applications. There is a need for evidence-based diagnostic and interventional US training programme that meets the unique needs of physical therapists and highlights the issues associated with the scope of practice and licensing.

Beyond training, it is important to consider that although diagnostic and/or interventional US may fall within the scope of physical therapy (assuming suitable training is obtained) in some jurisdictions, for the majority this is not the case. Regardless of training or expertise, physical therapists should clarify their scope of practice for these US applications by contacting their regulatory body prior to performing diagnostic or interventional US. In many instances, a change in legislation to extend the scope of physical therapy practice in a jurisdiction may be required before therapists can use US in this manner.

In contrast to diagnostic and interventional US, and despite increasing evidence that demonstrates a role for RUSI in physical therapy, the field of RUSI lacks professional oversight, standard curriculum and regulation for training. These deficiencies have resulted in a paucity of high-quality, evidencebased training opportunities; a lack of standardisation in the performance and reporting of RUSI applications; and a potential for insufficiently trained operators. ${ }^{416768}$

\section{A FRAMEWORK FOR US TRAINING FOR PHYSICAL THERAPISTS}

As competent use of US for point-of-care or research purposes is not part of an entry to practice skill set, and generally absent in physical therapy entry-to-practice education programme, access to postgraduate education to support safe competent practice is needed. The sections that follow contain key competencies, options for delivery and learning objectives for this training. This content is based on literature review, and the extensive experience of developing and delivering US training to physical therapists by the authors, in conjunction with consultation and collaboration with numerous medical and sonographic professionals and professional organisations (eg, the British Medical Ultrasound Society), over the last 30 years. The intent of this material is to provide a foundation for individuals and organisations developing or evaluating RUSI, diagnostic or interventional US courses for physical therapists.

\section{Core competencies for US use by physical therapists}

The Canadian National Physiotherapy Advisory group defines an essential competency as the repertoire of measurable knowledge, skills and attitudes required by a physical therapist throughout their professional career. ${ }^{70}$ For physical therapists that use US in their practice, this includes the knowledge, skills and attitudes associated with safe, competent conduct and interpretation of US examinations. Fundamental competencies that span all uses of US by physical therapists and those unique to RUSI, diagnostic, interventional or research US examinations are outlined in Box 1.

\section{Delivery format}

Given that physical therapists who utilise US must demonstrate common fundamental and application-specific competencies, a competency-based education model of training is suggested. Competency-based education is driven by the 'product' rather than the process, ${ }^{71}{ }^{72}$ whereby learning outcomes are first identified and the curriculum is built in discrete 'steps' to ensure that students achieve the competencies described in the learning outcomes. In the case of US, 'steps' could take the form of an 'introductory' (ie, fundamental knowledge and proficiency) module followed by completion of one, or several, 'application-specific' modules (ie, RUSI, diagnostic or interventional). The delivery of each module could take the form of didactic and/or practical instruction with each culminating in a practical examination of safety, technical aspects, and image generation and interpretation competence. This approach allows flexibility for the addition of future US applications and could be supplemented with formal or informal mentorship, supervision and case-based examination. In addition to instruction by physical therapists who are experts in this field, training should, where possible, involve other imaging disciplines (eg, sonographer/radiologist/interventional radiologists) and focus on the pathologies and disorders that physical therapists treat. Furthermore, it is important to consider that training could be provided in many settings (eg, entry and post-professional level) and through different delivery mechanisms (eg, pre-reading and exams, online resources, practical courses, virtual mentoring and supervised scanning or review of stored images or real-time clips for quality assurance, etc). There may also be value in embedding training within existing coursework in entry-to-practice programme (eg, electrophysical agents, anatomy, orthopaedics, neurology, professional issues courses or yearly or programme-end capping exercises).

\section{Curriculum}

The competent conduct and interpretation (including background knowledge) of US examinations vary by the level of operator skill (eg, introductory vs advanced) and application 
Box 1. Summary of fundamental competencies

(knowledge, skills and attitudes) for safe and efficacious use of US by physical Therapists*

Fundamental Knowledge, Skills, Attitudes

- Professional and ethical considerations

- Communication

- Basic anatomy and physiology

- US basic physics

- US safety, upkeep and hygiene

- Basic US terminology and instrumentation

- Basic US image generation and optimisation

- Basic US interpretation including artefact

RUSI Competencies Knowledge, Skills, Attitudes

- Physical therapy scope and history of RUSI

- Detailed anatomy and physiology

- Theoretical foundations of neuromuscular function and dysfunction

- RUSI terminology and instrumentation

- RUSI image generation and optimisation

- RUSI interpretation

- Special issues for specific body regions and applications

- Integration of RUSI findings for prevention and management of clinical conditions

- Evaluate the use of RUSI in clinical practice

Diagnostic US Knowledge, Skills, Attitudes

- Physical therapy scope and history of diagnostic US

- Detailed anatomy and physiology

- Theoretical foundations of pathoanatomical and biopsychosocial models of pain

- Diagnostic US terminology and instrumentation

- Diagnostic US image generation and optimisation

- Diagnostic US interpretation

- Integration of diagnostic US for prevention and management of clinical conditions

- Evaluate the use of diagnostic US in clinical practice

Interventional US Knowledge, Skills, Attitudes

- Physical therapy scope and history of interventional US

- Detailed anatomy and physiology

- Interventional US safety

- Interventional US needle guidance principles, methods and accuracy

- Interventional US terminology and instrumentation

- Interventional US image generation and optimisation

- Interventional US interpretation

- Integration of interventional US for prevention and management of clinical conditions

- Evaluate the use of interventional US in clinical practice

Research US Knowledge, Skills, Attitudes

- History of physical therapy research using US

- Relevant anatomy and physiology

- Research context background knowledge

- Study design and research methodology

- Research US methodology and approaches

- Research US ethics and safety

- Research US terminology, instrumentation and applications

- Research US image generation and optimisation

- Research US interpretation

- Research US dissemination
Box 1 Continued

*It is recommended that all physical therapists that use US meet the fundamental competencies followed by one of the application specific competencies.

RUSI, rehabilitative ultrasound imaging; US, ultrasound.

(eg, RUSI, diagnostic, interventional, research). Suggested learning outcomes for 'introductory' and 'application' modules or courses are outlined in online supplementary table 2 located in.

\section{RECOMMENDATION AND FUTURE DIRECTIONS}

Future efforts should focus on developing international standards for self-governance of US use by physical therapists and ensuring that training and practice standards are identified, reached and maintained. Failure to do this may result in restricted use of US by physical therapists in various jurisdictions. Greater interprofessional exposure to the use of US by physical therapists is needed to avoid inaccurate assumptions about professional infringement and to foster understanding of the unique applications of US that occur within physical therapy practice. Finally, it is imperative that physical therapists continue to provide evidence that US enhances the quality, effectiveness (including cost) and efficacy of physical therapy management.

\section{Author affiliations}

'Department of Physical Therapy, Faculty of Rehabilitation Medicine, University of Alberta, Edmonton, Alberta, Canada

${ }^{2}$ Health and Rehabilitation Research Institute, School of Clinical Sciences, Auckland

University of Technology, Auckland, New Zealand

${ }^{3}$ School of Health and Rehabilitation Sciences, The University of Queensland,

Brisbane, Queensland, Australia

${ }^{4}$ Department of Physiotherapy and Performance Science, University College Dublin,

Dublin, Ireland

${ }^{5}$ School of Allied Health Sciences, Griffith University, Brisbane, Queensland, Australia

${ }^{6}$ Departmento de Enfermeria y Fisioterapia, Universidad de Alcala de Henares,

Madrid, Spain

${ }^{7}$ Departamento de Fisioterapia, Universidad Francisco de Victoria, Madrid, Spain

${ }^{8}$ Walter Reed Army Institute of Research, Silver Spring, Maryland, USA

${ }^{9}$ School of Health Professions and Rehabilitation Sciences, University of

Southampton, Southampton, UK

Acknowledgements The authors acknowledge Drs C. Calvo-Lobo and A. GarridoMarin for their invaluable efforts and support of the International Symposium hosted by the Universidad Francisco de Vitoria and the Spanish Society of Ultrasound in Physiotherapy in Madrid, Spain (2016) as well as the support of the Arthritis Research UK Centre for Sport, Exercise and Osteoarthritis, and University of Alberta, Canada.

Contributors JLW drafted the first version of the manuscript with assistance from RE and MJS. All authors contributed to discussions leading up to the manuscript, contributed to sections of the manuscript and approved the final version of the manuscript. MJS, DST, PWH, JH and JLW were involved in the initial meetings to discuss the standardisation of USI education for physical therapist at the first international meeting on RUSI in 2006. DST hosted the first international meeting on Rehabilitative Ultrasound Imaging in San Antonio, USA. SFC and JLAB hosted the second RUSI meeting in Madrid, Spain.

Funding The authors acknowledge the support of the Arthritis Research UK Centre for Sport, Exercise and Osteoarthritis (grant number 21595).

Competing interests All authors have completed the ICMJE uniform disclosure forms at www.icmje.org/coi_disclosure.pdf.

Patient consent for publication Not required.

Provenance and peer review Not commissioned; externally peer reviewed.

Open access This is an open access article distributed in accordance with the Creative Commons Attribution 4.0 Unported (CC BY 4.0) license, which permits others to copy, redistribute, remix, transform and build upon this work for any 
purpose, provided the original work is properly cited, a link to the licence is given, and indication of whether changes were made. See: https://creativecommons.org/ licenses/by/4.01.

\section{ORCID iDs}

Jackie L Whittaker http://orcid.org/0000-0002-6591-4976

Paul William Hodges http://orcid.org/0000-0002-1206-9107

\section{REFERENCES}

1 Stokes M, Young A. Measurement of quadriceps Cross-sectional area by ultrasonography: a description of the technique and its applications in physiotherapy. Physiotherapy Practice 1986;2:31-6.

2 Young A, Stokes M, Crowe M. Size and strength of the quadriceps muscles of old and young women. Eur J Clin Invest 1984;14:282-7.

3 Young A, Stokes M, Crowe M. The size and strength of the quadriceps muscles of old and young men. Clin Physiol 1985;5:145-54.

4 Young A, Hughes I. Ultrasonography of muscle in physiotherapeutic practice and research. Physiotherapy 1982;68:187-90

5 Young A, Hughes I, Russell P, et al. Measurement of quadriceps muscle wasting by ultrasonography. Rheumatology 1980;19:141-8

6 Teyhen DS, Gill NW, Whittaker JL, et al. Rehabilitative ultrasound imaging of the abdominal muscles. J Orthop Sports Phys Ther 2007;37:450-66.

7 Whittaker JL, Teyhen DS, Elliott JM, et al. Rehabilitative ultrasound imaging: understanding the technology and its applications. J Orthop Sports Phys Ther 2007:37:434-49.

8 Whittaker JL, Thompson JA, Teyhen DS, et al. Rehabilitative ultrasound imaging of pelvic floor muscle function. J Orthop Sports Phys Ther 2007:37:487-98.

9 Teyhen D. Rehabilitative ultrasound imaging symposium San Antonio, tx, may 8-10, 2006. J Orthop Sports Phys Ther 2006:36:A1-3.

10 Networking session on Rehabilitative Ultrasound Imaging (RUSI). IFOMPT 2012 Conference - Rendez-vous of Hands and Minds. Quebec City Canada, 2012

11 Fernández-Carnero S, Calvo-Lobo C, Garrido-Marin A, et al. Rehabilitative Ultrasound Imaging Symposium in Physiotherapy - Madrid, Spain, 3-5 June 2016. British Journal of Sports Medicine 2018;52(Suppl 2):a1-6.

12 World Confederation for physical therapy (WCPT). policy statement: description of physical therapy. London UK: WCPT 2017.

13 Canadian Association of Radiologists. Position statement of the use of point of care ultrasound, 2013.

14 Bailey LB, Beattie PF, Shanley E, et al. Current rehabilitation applications for shoulder ultrasound imaging. J Orthop Sports Phys Ther 2015;45:394-405.

15 Cuellar WA, Wilson A, Blizzard CL, et al. The assessment of abdominal and multifidus muscles and their role in physical function in older adults: a systematic review. Physiotherapy 2017;103:21-39.

16 Jansen J, Weir A, Dénis $R$, et al. Resting thickness of transversus abdominis is decreased in athletes with longstanding adduction-related groin pain. Manual Therapy 2010;15:200-5.

17 Teyhen DS, Williamson JN, Carlson NH, et al. Ultrasound characteristics of the deep abdominal muscles during the active straight leg raise test. Arch Phys Med Rehabil 2009;90:761-7

18 Hodges P, Holm AK, Hansson T, et al. Rapid atrophy of the lumbar multifidus follows experimental disc or nerve root injury. Spine 2006;31:2926-33.

19 Hebert JJ, Fritz JM, Thackeray A, et al. Early multimodal rehabilitation following lumbar disc surgery: a randomised clinical trial comparing the effects of two exercise programmes on clinical outcome and lumbar multifidus muscle function. Br J Sports Med 2015;49:100-6.

20 Hides JA, Lambrecht G, Stanton WR, et al. Changes in multifidus and abdominal muscle size in response to microgravity: possible implications for low back pain research. Eur Spine J 2016:25:175-82.

21 Cruz-Montecinos C, Cerda M, Sanzana-Cuche R, et al. Ultrasound assessment of fascial connectivity in the lower limb during maximal cervical flexion: technical aspects and practical application of automatic tracking. BMC Sports Sci Med Rehabil 2016;8.

22 Kasehagen $B$, Ellis R, Pope $R$, et al. Assessing the reliability of ultrasound imaging to examine peripheral nerve excursion: a systematic literature review. Ultrasound Med Biol 2018;44:1-13.

23 Lee D, Hodges PW. Behavior of the Linea alba during a Curl-up task in diastasis rectus abdominis: an observational study. J Orthop Sports Phys Ther 2016;46:580-9.

24 Stafford RE, Ashton-Miller JA, Constantinou CE, et al. Novel insight into the dynamics of male pelvic floor contractions through transperineal ultrasound imaging. Journal of Urology 2012;188:1224-30.

25 Langevin HM, Stevens-Tuttle D, Fox JR, et al. Ultrasound evidence of altered lumbar connective tissue structure in human subjects with chronic low back pain. BMC Musculoskelet Disord 2009;10. 1471-2474-10-151 [pii].

26 Hides J, Stanton W, Mcmahon S, et al. Effect of stabilization training on multifidus muscle cross-sectional area among young elite cricketers with low back pain. J Orthop Sports Phys Ther 2008;38:101-8.
27 Hides JA, Mendis MD, Franettovich Smith MM, et al. Association between altered motor control of trunk muscles and head and neck injuries in elite footballers - an exploratory study. Manual Therapy 2016;24:46-51.

28 Hides JA, Stanton WR. Predicting football injuries using Size and ratio of the multifidus and quadratus lumborum muscles. Scand J Med Sci Sports 2017;27:440-7.

29 Whittaker JL, Emery CA. Impact of the FIFA 11+ on the structure of select muscles in adolescent female soccer players. Phys Ther Sport 2015;16:228-35.

30 Teyhen DS, Childs JD, Dugan JL, et al. Effect of two different exercise regimens on trunk muscle morphometry and endurance in soldiers in training. Physical Therapy 2013;93:1211-24

31 Koppenhaver SL, Fritz JM, Hebert JJ, et al. Association between history and physical examination factors and change in lumbar multifidus muscle thickness after spinal manipulation in patients with low back pain. J Electromyogr Kinesiol 2012;22:724-31

32 Chen L, Luo D, Yu X, et al. Predicting stress urinary incontinence during pregnancy: combination of pelvic floor ultrasound parameters and clinical factors. Acta Obstet Gynecol Scand 2018. [Epub ahead of print: 12 May 2018].

33 Stafford RE, van den Hoorn W, Coughlin G, et al. Postprostatectomy incontinence is related to pelvic floor displacements observed with trans-perineal ultrasound imaging. Neurourol Urodyn 2018;37:658-65.

34 Dietz HP, Wilson PD, Clarke B. The use of perineal ultrasound to quantify levator activity and teach pelvic floor muscle exercises. Int Urogynecol J 2001;12:166-9.

35 Van Holsbeeck MT, Introcaso JH, Ultrasound M. PA. Philadelphia: Mosby Press, 2001.

36 McAuliffe S, McCreesh K, Culloty F, et al. Can ultrasound imaging predict the development of Achilles and patellar tendinopathy? A systematic review and metaanalysis. Br J Sports Med 2016:50:1516-23.

37 Strike KL, lorio A, Jackson S, et al. Point of care ultrasonography in haemophilia care: recommendations for training and competency evaluation. Haemophilia 2015;21:828-31.

38 Querol F, Rodriguez-Merchan EC. The role of ultrasonography in the diagnosis of the musculo-skeletal problems of haemophilia. Haemophilia 2012;18:e215-26.

39 Ellis R, Blyth R, Arnold N, et al. Is there a relationship between impaired median nerve excursion and carpal tunnel syndrome? A systematic review. J Hand Ther 2017:30:3-12

40 De Smet AA, Winter TC, Best TM, et al. Dynamic sonography with valgus stress to assess elbow ulnar collateral ligament injury in baseball pitchers. Skeletal Radiol 2002:31:671-6.

41 Ellis R, De Jong R, Bassett S, et al. Exploring the clinical use of ultrasound imaging: a survey of physiotherapists in New Zealand. Musculoskelet Sci Pract 2018;34:27-37.

42 Finnoff JT, Hall MM, Adams E, et al. American medical Society for sports medicine (AMSSM) position statement: Interventional musculoskeletal ultrasound in sports medicine. Br J Sports Med 2015;49:145-50.

43 Leow MQH, Cao T, Lee SHE, et al. Ultrasonography in acupuncture: potential uses for education and research. Acupunct Med 2016;34:320-2.

44 Calvo-Lobo C, Diez-Vega I, Martínez-Pascual B, et al. Tensiomyography, sonoelastography, and mechanosensitivity differences between active, latent, and control low back myofascial trigger points: a cross-sectional study. Medicine 2017:96:e6287.

45 Arias-Buría JL, Truyols-Domínguez S, Valero-Alcaide R, et al. Ultrasound-guided percutaneous electrolysis and eccentric exercises for subacromial pain syndrome: a randomized clinical trial. Evidence-Based Complementary and Alternative Medicine 2015;2015:1-9.

46 Abat F, Gelber PE, Polidori F, et al. Clinical results after ultrasound-guided intratissue percutaneous electrolysis $(E P I \circledast)$ and eccentric exercise in the treatment of Patellar tendinopathy. Knee Surg Sports Traumatol Arthrosc 2015;23:1046-52.

47 Tucker K, Hodges PW, Van den Hoorn W, et al. Does stress within a muscle change in response to an acute noxious stimulus? PLOS ONE 2014;9:e91899.

48 Whittaker JL, McLean L, Hodder J, et al. Association between changes in electromyographic signal amplitude and abdominal muscle thickness in individuals with and without lumbopelvic pain. J Orthop Sports Phys Ther 2013:43:466-77.

49 Van K, Hides JA, Richardson CA. The use of real-time ultrasound imaging for biofeedback of lumbar multifidus muscle contraction in healthy subjects. J Orthop Sports Phys Ther 2006;36:920-5.

50 Konofagou EE, Langevin HM. Using ultrasound to understand acupuncture. Acupuncture needle manipulation and its effect on connective tissue. IEEE Eng Med Biol Mag 2005;24:41-6

51 Ellis R, Rohan M, Fox J, et al. Ultrasound Elastographic measurement of sciatic nerve displacement and shear strain during active and passive knee extension. J Ultrasound Med 2018

52 Coombes BK, Tucker K, Vicenzino B, et al. Achilles and patellar tendinopathy display opposite changes in elastic properties: a shear wave elastography study. Scand J Med Sci Sports 2018;28:1201-8.

53 Andrade RJ, Nordez A, Hug F, et al. Non-invasive assessment of sciatic nerve stiffness during human ankle motion using ultrasound shear wave elastography. J Biomech 2016;49:326-31.

54 Hug F, Ouellette A, Vicenzino B, et al. Deloading tape reduces muscle stress at rest and during contraction. Med Sci Sports Exerc 2014;46:2317-25. 
55 Coppieters MW, Hough AD, Dilley A. Different nerve-gliding exercises induce different magnitudes of median nerve longitudinal excursion: an in vivo study using dynamic ultrasound imaging. J Orthop Sports Phys Ther 2009;39:164-71.

56 Heales LJ, Tucker K, Vicenzino B, et al. A comparison of fine wire insertion techniques for deep finger flexor muscle electromyography. J Electromyogr Kinesiol 2018:41:77-81.

57 Hodges PW, Butler JE, McKenzie DK, et al. Contraction of the human diaphragm during rapid postural adjustments. J Physiol 1997;505:539-48.

58 Costa LOP, Maher CG, Latimer J, et al. Reproducibility of rehabilitative ultrasound imaging for the measurement of abdominal muscle activity: a systematic review. Physical Therapy 2009;89:756-69.

59 Hebert JJ, Koppenhaver SL, Parent EC, et al. A systematic review of the reliability of rehabilitative ultrasound imaging for the quantitative assessment of the abdominal and lumbar trunk muscles. Spine 2009;34:E848-E856.

60 Koppenhaver SL, Hebert JJ, Parent EC, et al. Rehabilitative ultrasound imaging is a valid measure of trunk muscle size and activation during most isometric sub-maximal contractions: a systematic review. Aust J Physiother 2009:55:153-69.

61 O'Sullivan C, Meaney J, Boyle G, et al. The validity of rehabilitative ultrasound imaging for measurement of trapezius muscle thickness. Manual Therapy 2009:14:572-8.

62 Koppenhaver SL, Parent EC, Teyhen DS, et al. The effect of averaging multiple trials on measurement error during ultrasound imaging of transversus abdominis and lumbar multifidus muscles in individuals with low back pain. J Orthop Sports Phys Ther 2009;39:604-11.
63 Whittaker JL, Emery CA. Sonographic measures of the gluteus medius, gluteus minimus, and vastus medialis muscles. J Orthop Sports Phys Ther 2014;44:627-32.

64 Dones VC, Grimmer K, Thoirs K, et al. The diagnostic validity of musculoskeletal ultrasound in lateral epicondylalgia: a systematic review. BMC Med Imaging 2014; 14.

65 James SLJ, Ali K, Pocock C, et al. Ultrasound guided dry needling and autologous blood injection for patellar tendinosis. Br J Sports Med 2007;41:518-21.

66 Ryu J, Jeong WK. Current status of musculoskeletal application of shear wave elastography. Ultrasonography 2017;36:185-97.

67 Potter CL, Cairns MC, Stokes M. Use of ultrasound imaging by physiotherapists: a pilot study to survey use, skills and training. Manual Therapy 2012;17:39-46.

68 Jedrzejczak A, Chipchase LS. The availability and usage frequency of real time ultrasound by physiotherapists in South Australia: an observational study. Physiother Res Int 2008;13:231-40.

69 WHO Study Group on Training in Diagnostic Ultrasound. Training in diagnostic ultrasound: essentials, principles and standards. Geneva: World Health Organization, 1998.

70 National Physiotherapy Advisory Group. Essential competency profile for physiotherapists in Canada. Ottawa, 2009.

71 Frank JR, Snell LS, Cate OT, et al. Competency-based medical education: theory to practice. Med Teach 2010;32:638-45.

72 Gruppen LD, Burkhardt JC, Fitzgerald JT, et al. Competency-based education: programme design and challenges to implementation. Med Educ 2016;50:532-9. 